\title{
Pilotagem de fármacos
}

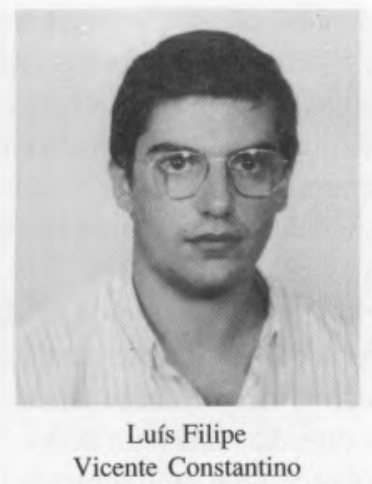

Licenciado em Ciências Farmacêuticas, Ramo Farmácia Industrial, pela Faculdade de Farmácia de Lisboa em 1985. Monitor na Faculdade de Farmácia de Lisboa (1983-1985). Assistente Estagiário na Faculdade de Farmácia de Lisboa (1985-1989).

Assistente na Faculdade de Farmácia de Lisboa (1989-). Trabalhou em Portugal (LNETI) e nos EUA (M.D. Anderson Hospital em Houston e National Jewish Center for Immunology and Respiratory Medicine em Denver) no campo de aplicações terapêuticas de liposomas. Actualmente faz investigação na FFL em modelos biomiméticos para estudo de metabolismo de $\mathrm{N}, \mathrm{N}$-dimetilamidas antitumorais.

\section{Introdução}

A aplicação do arsenal terapêutico disponível está frequentemente limitada pela acção indiscriminada dos fármacos e pela sua dificuldade em atingir preferencialmente as áreas que necessitam de tratamento. Quando se administra um fármaco este não se dirige apenas aos seus órgãos alvo mas distribui-se também por outros tecidos, daí muitas vezes o aparecimento de efeitos secundários e toxicidade elevada. Por outro lado o desenvolvimento de novos fármacos mais selectivos é muito dispendioso, extremamente lento e muitas vezes incerto.

Recentemente surgiu uma nova abordagem ao problema que consiste em dirigir a investigação não para o desenvolvimento de novos fármacos mas sim para a optimização dos já existentes através de vários tipos de sistemas terapêuticos os quais se podem dividir em duas grandes categorias:

- os sistemas de libertação programada, onde se controla a cinética de libertação do fármaco, como sejam os sistemas transdérmicos ou os implantáveis de libertação programada. - os sistemas de transporte de fármacos onde a aposta é mais audaciosa e se tenta interferir na distribuição do fármaco com o intuito de atingir determinados tecidos em detrimento de outros. Os lipossomas, as microesferas, os complexos fármacoanticorpo e os eritrócitos são exemplos deste tipo de sistemas terapêuticos.

Com o direccionamento de fármacos não se pretende modificar o seu modo de acção a nível molecular mas tão só aumentar a selectividade pelo uso de transportadores que, sem nenhuma actividade farmacológica intrínseca, possam guiar o fármaco até ao seu órgão alvo.

Apesar do conceito de direccionamento ter mais de um século só há cerca de 20 anos foi possível iniciar estudos experimentais efectivos que originaram uma vasta gama de sistemas sintéticos, macromoleculares ou celulares que têm sido testados com vista à sua utilização clínica.

\section{Anticorpos}

Anticorpos são proteínas que são formadas em resposta a determinados agentes (antigéneos) e que reagem especificamente com eles inactivando-os. Uma condição fundamental para o aparecimento do Anticorpo é que o agente seja reconhecido como estranho ao organismo. 
Recentemente com o advento dos anticorpos monoclonais tornou-se possível preparar quantidades apreciáveis de anticorpos dirigidos contra antigéneos associados com tumores, vírus ou bactérias, criando assim a possibilidade dos anticorpos serem estudados como meio de dirigir fármacos para alvos específicos.

A ligação de fármacos a anticorpos é potencialmente uma forma de lhes aumentar a selectividade especialmente quando estes são providos de uma citotoxicidade elevada como é o caso dos anticancerígenos.

Esta abordagem está a ter um sucesso particular com a utilização de toxinas muito poderosas em lugar de agentes citotóxicos convencionais. Estas macromoléculas são normalmente compostas de duas cadeias polipeptídicas, uma $\beta$, responsável pela ligação às células, e uma $\alpha$, responsável pela acção citotóxica - inibição da síntese proteica. Vários investigadores têm substituído a cadeia $\beta$ por anticorpos de molde a direccionar o complexo para células específicas e ao mesmo tempo evitar efeitos laterais severos que poderiam acontecer se a toxina nativa fosse libertada para a circulação. Um dos problemas que se põe aos investigadores é de ordem química: as técnicas usadas para ligar o fármaco ao anticorpo, levam muitas vezes à destruição de um deles ou à alteração da estrutura terceária das moléculas o que pode originar uma farmacocinética diferente do previsto.

Outro dos problemas é a possibilidade de existência em circulação de antigéneos-alvo os quais ao ligarem-se ao complexo fármaco-anticorpo impediriam a sua ligação às células. No entanto este problema a surgir poderia ser ultrapassado pelo doseamento dos antigéneos circulantes e a sua inactivação por meio da quantidade apropriada de anticorpo.

\section{Outras macromoléculas}

Para além dos anticorpos, muitas outras macromoléculas têm sido estudadas como transportadoras de fármacos, apresentando como estes algumas vantagens não negligenciáveis uma vez que a sua solubilidade e tamanho reduzido thes permite ganhar acesso a regiões inacessíveis a outros transportadores, ao mesmo tempo que evita que sejam removidos rapidamente da circulação.

O número destes potenciais transportadores é enorme, virtualmente todas as proteínas do plasma desde as lipoproteínas de alta densidade até à albumina ou fibrinogénio têm sido propostas. Uma solução engenhosa consiste em associar fármacos a péptidos por via de ligações que possam ser quebradas pela plasmina. Uma vez que esta enzima está em elevadas concentrações nas imediações de tumores o transportador é cindido localmente sendo o fármaco libertado no seu local de acção.

As glicoproteínas pelo facto de possuirem afinidade para receptores celulares específicos têm também sido estudadas. Estas moléculas possuem resíduos de carbohidratos que lhes permite a ligação selectiva a certas células. Por exemplo a interacção de glicoproteínas com receptores presentes nas células do parênquima hepático leva à sua internalização por endocitose, portanto é possível com estas moléculas pilotar fármacos para estas células. Numerosos exemplos do seu uso têm sido citados em terapia anti-viral, anti-parasítica e antitumoral.
Por outro lado transportadores baseados em macromoléculas sintéticas como polietilenoglicol, polivinilpirrolidona ou poliaminoácidos têm também sido propostos sendo em geral o seu direccionamento mais difícil de conseguir devido à menor especificidade associada ao transportador.

\section{Eritrócitos}

É possível lisar glóbulos vermelhos e fechar de novo as suas membranas de modo a que estes aprisionem no seu interior água e quaisquer solutos hidrosolúveis da solução onde se encontram.

Este procedimento permite encapsular em «células fantasma» uma variada gama de fármacos e enzimas.

Propôs-se que os glóbulos vermelhos poderiam ser incorporados com enzimas as quais promoveriam, enquanto estavam em circulação, a degradação de moléculas indesejáveis como por exemplo a aspargina em doentes com leucemia, uma vez que este aminoácido é essencial para as células leucémicas não o sendo para as células normais.

No entanto devido à complexicidade destes transportadores existem problemas evidentes quando se pensa na sua implantação clínica principalmente tendo como concorrentes os lipossomas que são mais bem definidos quimicamente e não têm o potencial de antigenicidade associado aos eritrócitos.

\section{Lipossomas}

Dentro dos vários tipos de sistemas de transporte actualmente em investigação os mais estudados têm sido os lipossomas provavelmente devido à sua toxicidade praticamente nula, facilidade de preparação, ao facto de serem formados a partir de substâncias naturais e ainda à vasta gama de fármacos possíveis de incorporação.

Há cerca de 25 anos foi observado que a hidratação de um filme de fosfolípidos dava origem a vesículas às quais se convencionou chamar lipossomas. As moléculas lipídicas arranjam-se em vesículas esféricas, que consistem numa ou mais bicamadas rodeando um espaço interno aquoso. As bicamadas são constituídas por fosfolípidos e têm uma estrutura semelhante à da membrana celular, pelo que os lipossomas têm sido muito usados como modelos membranares.

O valor potencial dos lipossomas em terapêutica deriva da facilidade que estas vesículas têm de incorporar tanto substâncias hidrofílicas como lipofílicas. As primeiras são encapsuladas no espaço interno aquoso, enquanto que as segundas são incorporadas nas membranas lipídicas.

Dependendo do modo de preparação os lipossomas variam consideravelmente em tamanho e número de lamelas presentes. De um modo geral, os lipossomas podem-se dividir em: -vesículas unilamelares, se apenas possuirem uma bicamada de fosfolípidos;

-vesículas multilamelares, se possuirem várias bicamadas de fosfolípidos.

Ambos os tipos de vesículas podem ser divididos de acordo com o seu diâmetro em pequenas $(0.025-0.1 \mu \mathrm{m})$ e grandes $(0.1-100 \mu \mathrm{m})$.

A classificação, pode ser também feita, atendendo ao seu 
modo de preparação, surgindo assim várias subdivisões para cada tipo de vesículas.

O tipo mais comum de lipossomas são os MLV (vesículas multilamelares grandes), estruturas de espaços aquosos concêntricos separados por bicamadas lipídicas que muitas vezes é visualizada como se fosse uma cebola. A sonicação pode reduzir MLV e SUV (vesículas unilamelares pequenas) as quais são constituídas por um espaço interno aquoso rodeado por uma única bicamada lipídica.

As propriedades físicas dos lipossomas dependem em parte da sua composição química sendo possível usar diferentes fosfolípidos, naturais ou sintéticos e incluir esteróides, ácidos gordos ou uma variedade de outros compostos com ou sem carga. As propriedades físicas dos lipossomas dependem ainda da temperatura, $\mathrm{pH}$, força iónica e presença de catiões divalentes.

Embora os lipossomas tenham sido administrados por diversas vias foi sem dúvida pela via intravenosa que se obtiveram os maiores êxitos experimentais. Os lipossomas uma vez em circulação interagem com os órgãos ricos em células do sistema reticuloendotelial (SRE) nomeadamente fígado, baço, medula óssea e pulmões sendo fagocitados pelos macrófagos aí existentes. Os macrófagos são células pertencentes ao SRE e estão na primeira linha das defesas do organismo tendo funções de fagocitose e destruição de corpos estranhos.

É no entanto possível manipulando a carga, a composição lipídica ou o tamanho dos lipossomas modular um pouco o comportamento in vivo destas vesículas.

Os lipossomas parecem pois ser o veículo ideal para dirigir fármacos para os macrófagos do SRE. Lipossomas de pequenas dimensões poderão também ser usados para dirigir fármacos para as células do parênquima de tecidos onde os capilares são suficientemente porosos para lhes dar passagem, como no fígado e rins. No entanto atingir células de outros tecidos com lipossomas intactos parece neste momento algo de muito difícil realização mesmo recorrendo a direccionamento por meio de anticorpos ligados aos lipossomas.

A utilização dos lipossomas em terapêutica tem sido explorada essencialmente de três modos:

- aumentar a entrega de fármaco no seu órgão alvo (quando este seja rico no SRE);

-diminuir a concentração de fármaco num tecido para o qual ele seja tóxico, tirando vantagem da alteração da farmacocinética provocada pela incorporação em lipossomas;

- diminuir a inactivação do fármaco enquanto em circulação ou a possibilidade de choque anafilático, uma vez que este está irreconhecível tanto pelo sistema imunitário como por enzimas que promovam a sua degradação.

Como era de esperar é no campo da interacção dos lipossomas com o SRE que se têm observado os resultados mais espectaculares. Devido a este sistema ser o alvo natural dos lipossomas consegue-se aumentar de várias vezes a concentração de fármaco nos órgãos alvo.

No que diz respeito ao SRE os lipossomas têm actuado de duas maneiras:

-introduzindo fármacos nas células que actuem sobre residentes indesejáveis que tanto podem ser micróbios como entidades químicas;

-introduzindo agentes que estimulem determinadas proprie- dades das células alvo como por exemplo a capacidade fagocitária dos macrófagos.

Um resultado bastante promissor foi obtido no combate à leishmaniose. A leishmaniose é uma doença tropical que pode revestir diversas formas e que afecta milhões de pessoas em todo o mundo.

O tratamento é muito difícil visto que os fármacos disponíveis são bastante tóxicos o que torna cerca de metade dos medicamentos ineficazes.

Esta doença tem a característica do parasita responsável, a leishmania, se alojar em células do SRE. Com encapsulação de derivados de antimónio em lipossomas conseguiram-se resultados bastante espectaculares nomeadamente a nível da infecção do fígado, tendo a dose necessária para matar 50\% dos parasitas diminuído cerca de 700 vezes, diminuindo em muito a toxicidade que acompanha o tratamento.

Ainda no mesmo campo há outros resultados que provam bem a utilidade dos lipossomas como sistemas terapêuticos; trata-se da encapsulação da 5-fluorocitosina e da griseofulvina conhecidos antifúngicos que demonstraram por via da encapsulação serem activos contra a forma visceral da leishmania actividade essa que nunca tinha sido demonstrada na forma livre.

Outra situação terapêutica em que se pode aproveitar a pilotagem natural dos lipossomas é a destoxificação de metais pesados muitos dos quais se acumulam em órgãos ricos no sistema retículo endotelial.

A destoxificação é feita com vários agentes quelantes como o BAL e o EDTA, no entanto os agentes quelantes disponíveis apresentam vários inconvenientes como penetração celular reduzida, excreção demasiado rápida e efeitos secundários variados.

$\mathrm{O}$ agente quelante só consegue na grande maioria dos casos remover a fracção de metal que se encontra no sangue, o qual é somente uma pequena parte do total. Os resultados da encapsulação destes fármacos em lipossomas são bastante prometedores pois conseguiu-se diminuir a velocidade de excreção do agente quelante, aumentar a sua captação pelos órgãos nos quais o metal se acumula, aumentar a sua penetração intracelular e portanto aumentar também a eliminação do metal indesejado em todos os casos estudados: plutónio, chumbo, ouro, mercúrio, ferro e itérbio.

Um importante aproveitamento da pilotagem natural dos lipossomas consiste em encapsular imunomoduladores para tratamento do cancro.

Os macrófagos são células multicompetentes que têm um papel importante na defesa do organismo, em particular parecem ser uma das barreiras primárias de destruição de células cancerígenas. Uma vez que as células cancerígenas têm diferenças em relação às células normais, os macrófagos podem ser activados a um estado tumoricida por intermédio de imunomodulares como as linfoquinas (ex: interfron gama) ou o muramil dipeptídeo.

Ficou demonstrado que estas substâncias são mais efectivas se forem dadas em lipossomas do que na forma livre. Numa experiência em que se tratou com muramil dipeptídeo encapsulado ratos portadores de tumores, $74 \%$ ficou livre de metastases visíveis enquanto que no tratamento com a forma livre apenas se conseguiu o mesmo resultado em $20 \%$ dos ratos. 
Entre as situações potenciais nas quais o direccionamento dos lipossomas para os macrófagos pode ser utilizado, uma das mais importantes é o uso de lipossomas como adjuvantes para vacinas.

Adjuvantes são substâncias que administradas juntamente com antigenes agem de uma maneira não específica de molde a aumentar a resposta imunitária.

De facto os macrófagos são peças importantes do processamento imunológico de certos antigenes e o principal sítio para a expressão de actividade para alguns adjuvantes. Os lipossomas ao dirigirem os antigenes para os macrófagos aumentam a sua eficácia na vacinação diminuindo assim a quantidade de antigene necessária e permitindo economias necessárias principalmente nos países mais pobres.

Os lipossomas têm ainda sobre os adjuvantes clássicos a vantagem de apresentarem uma menor toxicidade local e sistémica.

Das potenciais vacinas cujo estudo está mais adiantado é de realçar uma vacina contra a malária, no entanto muitas outras estão em estudo.

Outro campo onde os lipossomas têm tido resultados animadores é o da terapia antitumoral convencional. Os lipossomas têm actuado pela redução da toxicidade associada aos quimioterápicos, devido a promoverem uma alteração da farmacocinética destes fármacos.

Recentemente a química de síntese tem sido chamada insistentemente ao campo dos lipossomas. Uma vez que as substâncias lipofílicas conseguem ser encapsuladas em lipossomas com uma maior eficácia e uma maior estabilidade estão-se hoje em dia a sintetizar derivados lipofílicos de fármacos que se têm mostrado eficazes quando encapsulados em lipossomas mas cuja eficácia ou estabilidade era reduzida na forma livre. Também se tenta por outro lado sintetizar profármacos lipossolúveis derivados de fármacos já existentes e que consigam ser facilmente incorporados em lipossomas mas que uma vez no local de acção sejam facilmente degradados de modo a originarem novamente o princípio activo.

Por fim torna-se importante dizer que estão actualmente em fase de estudos clínicos em humanos várias formulações lipossomais entre as quais é de realçar as de anfotericina-b, doxorubicina, e derivados do muramil dipeptídeo esperandose que a sua comercialização possa ser iniciada dentro de pouco tempo.

\section{Microesferas}

Microesferas de albumina ou de polímeros sintéticos têm também sido sugeridas como transportadores de fármacos. Devido à sua natureza sintética este tipo de sistemas sofre a concorrência dos lipossomas no campo do direccionamento das microesferas para o sistema retículo-endotelial. No entanto e devido a serem permeáveis a moléculas pequenas como a ureia ou glucose, tem sido activamente estudado o seu uso extra corporal em que uma câmara contendo fármacos enzimas ou agentes quelantes imobilizados em microesferas seria atravessada por fluídos biológicos como o plasma procedendo-se assim à sua destoxificação.

Outra aplicação engenhosa das microesferas consiste em incorporar juntamente com o fármaco partículas ultrafinas de magnetite $\left(\mathrm{Fe}_{3} \mathrm{O}_{4}\right)$ tornando-as susceptíveis ao efeito de um campo magnético o que permite que as microesferas sejam retidas nos capilares na vizinhança de tumores, aplicando exteriormente um campo na vizinhança destes.

Este sistema permite que se crie na vizinhança do tumor um depósito de libertação contínua do fármaco.

\section{Conclusão}

Um longo caminho foi já percorrido desde o momento em que o conceito de pilotagem de fármacos foi pela primeira vez enunciado e poucos duvidarão que os próximos anos nos irão trazer novos avanços neste campo. Não se deve no entanto encarar nenhum destes sistemas como uma panaceia que poderá ser usada como vector em todo o tipo de situações pois corre-se o risco de sistemas bastante promissores virem a ser abandonados por falharem num campo para o qual nunca estiveram vocacionados.

\section{Referências}

- D. L. Wise, D. J. Trantolo, R. T. Marino, J. P. Kitchell, Adv. Drug Del. Rev, 19, 39 (1987).

- R. L. Juliano, Can. J. Physiol. Pharmacol., 56, 683 (1978).

- M. J. Poznanski, R. L. Juliano, Pharmacol. Rev., 36, 277 (1984).

- A. D. Bangham, M. M. Standish, J.C. Watkins, J.Mol. Biol., 13, 238 (1965).

- P. M. Ververgaert, A.J. Verkleij, P.F. Elbers, L. L. M. van Deenen, Biochim. Biophys. Acta, 311, 320 (1973).

- A. Rahman, A. Fumagalli, B. Barbieri, P. S. Schein, A. M. Casazza, Cancer Chemoter. Pharmacol., 16, 22 (1986).

-D. A. Eppstein, M. A. Pass, E. B. Frazer-Smith, C. G. Kurahara, P. L. Felgner, T. R. Matthews, R. V. Water, M. C. Venuti, G. H. Jones, R. Metha, G. Lopez-Berestein, Int. J. Imonutherapy, 2, 115 (1986).

- G. Lopez-Berestein, R. L. Hopfer, R. Metha, E. M. Hersh, R. L. Juliano, Antimicrob. Agents chemother., 25, 366 (1984).

- R. Perez-Soler, A. R. Khokhar, M. P. Hacker, G. Lopez-Berestein, Cancer Res., 46, 6269 (1986).

- L. Constantino, M. E. M. Cruz, Ciência Biológica, 12, 5 A 228 (1987).

- L. Constantino, M. E. M. Cruz, G. Lopez-Berestein, Abstracts do II Congresso Nacional de Ciências Farmacêuticas, 10-13 Novembro 1988, Montechoro, Portugal, pp. 49. Ed. Ordem dos Farmacêuticos Lisboa, 1988. - R. L. Juliano, D. Stamp, Biochem. Pharmacol., 27, 21 (1978).

- M. B. Yatvin, Med. Phis., 4, 149 (1982).

- T. M. Allen, A. Chonn, FEBS Letters, 223, 42 (1987).

- J. Lauterztain, Perez-Soller, A. R. Khokhar, R. A. Newman, G. LopezBerestein, Cancer Chemother. Pharmacol., 18, 93 (1986).

-F. Puisieux, J. Delattre, «Les Liposomes», Techniques et documentation Lavoisier, Paris, 1985.

- M. J. Ostro, «Liposomes», Ed. Marcel Dereck Inc., New York, 1983.

- «Targeting of Drugs», procedings of a NATO Advanced Study Institute on Targeting of Drugs, June 24-July 51981 Cape Sounion, Greece. Ed. G. Gregoriadis, J. Senior, A. Trouet, Plenum Press, New York, 1982.

- «Drug Targeting», Proceedings of the Synposiumon Drug Targeting, 3-5 October 1984 Nyon Switzerland. Ed. P. Buri, A. Gumma, Elsevier Science, Amsterdam, 1985. 


\section{Convite à Reflexão ...}

\section{Sem aspirina}

Não só o amor, segundo uma famosa autora no seu tempo, é feito de três quartos de curiosidade, mas, para mim, confesso, o foi também, agora, a consulta médica ao cuidado do alto dignitário e eminente prático de medicina tibetana, que visitou por alguns dias, poucos, Lisboa e o Porto.

$\mathrm{O}$ dr. Tendzin Chodrak, monge, creio, mais de tradição do que de mundivisão, é há muito médico pessoal do Dalai-Lama; um dos quatro que cuidam da sua saúde integral.

O curriculum do nosso hóspede, para nós, ocidentais, apresenta-se simultaneamente fascinante pelo seu exotismo, e banal, porque o exotismo não é exótico in loco. O exotismo é apenas a distância física, e mais ainda a distância entre as culturas.

Então, medicina alternativa. Tal como teria sido alternativa a nossa ciência médica para os alunos da (antiga) Faculdade de Medicina em Colina-de-Ferro, em Lassa. Nome que faz sonhar ...

[...] Tendzin Chodrak, pois: levanta-se do assento, saúda o paciente com uma pequena inclinação de cabeça, repetida, depois aperta suavemente a mão. À ocidental? De novo se instala no velho cadeirão. Embora não seja dele, é da casa, parece habitar esse lugar, esse sítio, há muito tempo. Traz consigo a imobilidade?

Toca a mão quase como um cego, sobe por ela até à tradicional tomada de pulso. Primeiro, a direita. Concentrado, personalizando o ouvir, através da pulsação, captando o corpo todo, ou melhor, o corpo-espírito, ou ainda melhor, o corpo-espírito-macro e microcosmo, numa integração holística («a parte está no todo, tudo está no todo») os olhos, as princípio semicerrados, agora fechados. Os dedos não deixam de se movimentar, suavemente. A seguir o pulso esquerdo, com dupla reacção activa: do pulso, do médico. A esquerda não é a direita? O corpo é dividido em sistemas?
[...] Fala. Ouve-se essa bela melopeia da língua tibetana. Sem perceber patavina (traduzida for me por um compatriota seu em inglês), teria gostado de ouvir ainda mais esse concerto, sem me lembrar que falava de mim, do meu corpo, do meu sangue, ou de um planeta qualquer, este ou outro em devir. Voz baixa, porém «articulada» com clareza. Cantado ... Uma boca acústica.

O rosto? Sem idade. Algumas feridas, saradas, mas cicatrizes visíveis: dizem que são os resíduos das torturas, lembrança dos 17 anos de estada em prisões chinesas, em campos de concentração, nos últimos tempos de chamada reeducação.

A receita, que decorre da consulta, também ela - recitada: dita-a para o seu assistente. A particularidade da medicina tibetana (mas não o era assim também dantes no Ocidente?) é o facto de os remédios serem fabricados pelos próprios médicos: vou então receber pelo correio uns remédios, alguns genéricos, um outro, se percebi bem, confeccionado à minha medida. Remédio único dessa farmacopeia reputada e preservada desde séculos, com o recente perigo de desaparecer, ela e os seus segredos.

Feita de plantas (418 ervas medicinais), minerais, cascas, a maior parte de origem himalaiana, poucos elementos animais. Como Mendeleiev na sua classificação previra novos elementos químicos ainda por identificar, esta ciência médica, representada por Tendzin Chodrak, prevê novas doenças por declarar, dividindo-as já em 18 categorias, e propondo para cada uma pista para um futuro tratamento.

Toda esta sombria futurologia médica mal corresponde ao seu sorriso de despedida. Ternura quase, um lampejo: o sorriso de um peregrino da imobilidade ...

Amanhã, prometo que vou reler Sidharta, de Hermann Hess. Somos ocidentais.

J. Listopad, "Diário de Notícias» 
